\title{
A DESIGUALDADE DE GÊNERO NA POLÍTICA E A SUB-REPRESENTAÇÃO FEMININA NOS PARLAMENTOS: UMA DISCUSSÃO AINDA NECESSÁRIA
}

\author{
Maxwel Gomes dos Santos* \\ Marcelo Barroso Lima Brito de Campos*
}

\section{Resumo:}

Este artigo propõe-se a discutir, sob o paradigma do Estado Democrático de Direito, em que medida a aplicação da cota de gênero contribui para fomentar a representatividade feminina na política. Utilizam-se a pesquisa bibliográfica e o método jurídico-dedutivo. Os resultados sinalizam que não há uma correlação necessária entre o preenchimento da cota de gênero e o incremento do número de candidatas eleitas. Os resultados apontam que a superação dessa desigualdade requer a discussão de outras possibilidades, tais como reserva de vagas no Legislativo, combate às candidaturas femininas fictícias e aplicação obrigatória de recursos nas campanhas femininas.

Palavras-chave: Direito eleitoral; Estado democrático de direito; Desigualdade de gênero; Participação política feminina; Representação política

\section{GENDER INEQUALITY IN POLITICS AND THE UNDER-REPRESENTATION OF WOMEN IN THE PARLIAMENTS: A DISCUSSION THAT STILL NEEDS TO BE ADDRESSED.}

\begin{abstract}
:
This study focuses, under the paradigm of the Democratic State of Law, on what extent the application of the gender quota contributes to foster the women representativeness in politics. A bibliographic research and the juridical-deductive method. The results indicate that there is no necessary correlation between the gender quota fulfilment and the increase of the number of elected candidates. The results also indicate that in order to overcome the inequality, it is necessary to discuss further possibilities, such as reserve of positions in the Legislative, combating fictitious feminine candidatures and compulsory implementation of resources on women's campaigns.
\end{abstract}

Keywords: Electoral law; Democratic State of Law; Gender inequality; Feminine political participation; Political representation

\section{INTRODUÇÃO}

No Brasil, a partir da Constituição de 1988, a cidadania e o pluralismo político

\footnotetext{
* Mestrando do Programa de Pós Graduação Strito Sensu em Instituições Sociais, Direito e Democracia, da Universidade FUMEC/MG. Possui Especialização Lato Sensu em Direito Eleitoral e Processual Eleitoral (CEUCLAR/SP). Bacharel em Direito (UNIMONTES). Professor de Ensino Superior na Universidade Estadual de Montes Claros - UNIMONTES. Analista Judiciário - Área Judiciária no Tribunal Regional Eleitoral de Minas Gerais. E-mail: maxwel.santos@ unimontes.br

** Pós-Doutorando em Direito Tributário (UFMG). Doutor em Direito Público (PUCMINAS). Mestre em Administração Pública (FJP). Professor da Graduação e do Mestrado em Direito (Universidade FUMEC). Procurador do Estado de Minas Gerais. Advogado. E-mail: marcelo.brito@fumec.br
}

Revista Brasileira de Filosofia do Direito | e-ISSN: 2526-012X | Encontro Virtual | v. 6 | n. 2 |

p. $55-74$ | Jul/Dez. 2020. 
ganharam um redimensionamento de sentido que supera a concepção restritiva de direitos políticos: votar, ser votado e possibilidade de existência de vários partidos políticos. Sob o paradigma do Estado Democrático de Direito, passam a compreender as diversas possibilidades de participação nas esferas públicas e políticas.

Em seu artigo $1^{\circ}$, a Constituição estabelece que a República Federativa do Brasil se constitui em Estado Democrático de Direito, cujos fundamentos são a soberania, a cidadania, a dignidade da pessoa humana, os valores sociais do trabalho e da livre iniciativa, bem como o pluralismo político. O parágrafo único do mesmo artigo deixa expresso que todo o poder emana do povo, que o exerce por meio de representantes eleitos ou diretamente, nos termos da Constituição (BRASIL, 1988).

Esse redimensionamento de sentido da cidadania e do pluralismo político pressupõe o Estado Democrático de Direito como medium e não como titular do poder político, que tem o povo como fonte da qual emana. A cidadania, nessa concepção, passa a ser o canal comunicativo, por meio do qual se forma a vontade política, a partir da síntese discursiva dos variados atores sociais, com seus diferentes projetos de vida, tal como deve ser o pluralismo político democrático.

A concretização da cidadania e do pluralismo político, necessariamente, pressupõe a igualdade como vetor e realiza-se num processo de convivência social, comprometido em construir uma sociedade livre, justa e solidária, sem preconceitos de origem, raça, sexo, cor, idade e quaisquer outras formas de discriminação, tal como previsto no artigo $3^{\circ}$ da Constituição (BRASIL, 1988).

Entretanto, a observação da realidade demonstra que a cidadania e a igualdade, mesmo formalmente previstas na Constituição, ainda não alcançaram plenamente as mulheres. Tendo como parâmetro de aferição a participação feminina na política e nos espaços de poder, constata-se uma sub-representação feminina nas eleições e, especialmente, na formação dos parlamentos.

O presente artigo propõe-se a discutir, sob o paradigma do Estado Democrático de Direito, em que medida a aplicação da cota de gênero nas eleições proporcionais tem contribuído para fomentar a representatividade feminina na política. Embora passados 25 anos da Lei $n^{\circ}$ 9.100/1995, que primeiro implementou a cota de gênero nas eleições, a desigualdade que marca a relação homem e mulher na esfera pública e nas instâncias de poder do Estado permanece arraigada e as mulheres ainda são sub-representadas nos parlamentos. 
O presente artigo utiliza-se da pesquisa bibliográfica e documental, bem como do método jurídico-dedutivo, com abordagem qualitativa. A discussão está estruturada a partir da seção que contextualiza o paradigma do Estado Democrático de Direto e a participação cidadã, tendo como referência a Constituição de 1988; em seguida aborda-se a desigualdade de gênero, a sub-representação feminina na esfera pública no Brasil e o déficit de legitimidade democrática que isso acarreta. Na sequência, discorre-se sobre as possibilidades de superação da desigualdade de gênero na política, identificando-se iniciativas já existentes e cogitando-se da pertinência de aprofundamento desse caminho.

\section{O PARADIGMA DO ESTADO DEMOCRÁTICO DE DIREITO E A PARTICIPAÇÃO CIDADÃ}

A Constituição de 1988, fundamentada na cidadania e na dignidade da pessoa humana, representa a síntese discursiva de uma sociedade plural, que tem no Estado Democrático de Direito o paradigma estruturante das relações jurídicas e sociais.

Já em seu artigo $1^{\circ}$, a Constituição estabelece que a República Federativa do Brasil se constitui em Estado Democrático de Direito, cujos fundamentos são a soberania, a cidadania, a dignidade da pessoa humana, os valores sociais do trabalho e da livre iniciativa, bem como o pluralismo político. O parágrafo único do mesmo artigo dispõe que todo o poder emana do povo, que o exerce por meio de representantes eleitos ou diretamente, nos termos da Constituição (BRASIL, 1988).

A cidadania e o pluralismo político, previstos no artigo $1^{\circ}$, incisos II e $\mathrm{V}$, da Constituição, ganharam uma dimensão que vai além da possibilidade de votar e ser votado e da existência de partidos políticos. Nas palavras de José Afonso da Silva, “A cidadania está aqui num sentido mais amplo do que o titular de direitos políticos. Qualifica os participantes da vida do Estado, o reconhecimento do indivíduo como pessoa integrada na sociedade estatal" (SILVA, 1998, p. 108).

Esse redimensionamento de sentido da cidadania e do pluralismo político pressupõe, portanto, o Estado Democrático de Direito como meio para o exercício legítimo do poder político, que emana do povo, e não como titular desse poder. A cidadania, nessa concepção, passa a ser o canal comunicativo, por meio do qual se forma a vontade política, a partir da síntese discursiva dos variados atores sociais, com seus diferentes projetos de vida, tal como deve ser o pluralismo político democrático. 
Este estudo adota a noção de paradigma como "um conjunto de ilustrações recorrentes e quase padronizadas de diferentes teorias nas suas aplicações conceituais, instrumentais e na observação.” (KUHN, 2013, p. 73). Ou seja, o paradigma é a referência amplamente aceita, pela qual o pesquisador contempla o objeto de sua observação. $\mathrm{O}$ paradigma do Estado Democrático de Direito é utilizado, neste artigo, como parâmetro de avaliação da participação feminina na esfera pública e o déficit de legitimidade democrática decorrente de sua sub-representação na formação das casas legislativas.

A cidadania, no paradigma do Estado Democrático de Direito, compreende as diversas possibilidades de participar e influir na determinação dos fins desejados pelo Estado e na concretização das políticas públicas. Realiza-se num processo de convivência social, comprometido em construir uma sociedade livre, justa e solidária, empenhado em garantir o desenvolvimento nacional; erradicar a pobreza e a marginalização e reduzir as desigualdades sociais e regionais; bem como promover o bem de todos, sem preconceitos de origem, raça, sexo, cor, idade e quaisquer outras formas de discriminação, conforme determina o artigo $3^{\circ}$, incisos I a IV, da Constituição de 1988 (BRASIL, 1988).

Ao refletir sobre a participação feminina no paradigma do Estado Democrático de Direito brasileiro, Jéssica Teles de Almeida está de acordo com o entendimento segundo o qual sua implantação não representou uma total ruptura com os paradigmas estatais que o precederam; trata-se, na verdade, de uma:

forma de estruturação do Estado que busca corrigir os problemas de legitimidade do Direito surgidas nos paradigmas anteriores. Em que pese os elementos legitimadores incrementados pelo Estado Democrático de Direito, a modernidade democrática já prenunciava que todos os cidadãos têm direito de participar do processo de escolha de seus representantes. Todavia, a experiência histórica revela que o processo de inclusão democrática foi lento e variável de acordo com o desenvolvimento social, cultural e político de cada povo. (ALMEIDA, 2015, p. 28).

O Estado Democrático de Direito é apresentado, por Silva (1998), como a evolução e superação dos paradigmas de Estado Liberal de Direito e do Estado Social de Direito. Aquele caracterizado pela submissão ao império da lei, pela divisão de poderes e o enunciado de garantia dos direitos individuais. Este, o Estado Social de Direito, caracterizado pelo compromisso de compatibilizar o capitalismo, como forma de produção, e a garantia de um repertório de direitos econômicos e sociais, servindo de base ao que se convencionou chamar 
de Welfare State. O Estado Democrático de Direito, por sua vez, configura um conceito novo, que incorpora os elementos componentes da ideia de Estado Democrático e de Estado Social de Direito, contudo os supera e tende a realizar a síntese do processo contraditório do mundo contemporâneo, como Estado promotor de justiça social, fundado na dignidade da pessoa humana (SILVA, 1998).

A democracia, nesse paradigma, há de ser um processo em que o poder emana do povo:

[...] e deve ser exercido em proveito do povo, diretamente ou por representantes eleitos (art. $1^{\circ}$, parágrafo único); participativa, porque envolve a participação crescente do povo no processo decisório e na formação dos atos de governo, pluralista, porque respeita a pluralidade de ideias, culturas e etnias e pressupõe assim o diálogo entre opiniões e pensamentos divergentes e a possibilidade de convivência de formas de organização e interesses diferentes da sociedade; há de ser um processo de liberação da pessoa humana das formas de opressão que não depende apenas do reconhecimento formal de certos direitos individuais, políticos e sociais, mas especialmente da vigência de condições econômicas suscetíveis de favorecer o seu pleno exercício. (SILVA, 1998, p. 123-124).

Em relação à representação política, há uma dissociação perceptível entre o ideal de Estado Democrático de Direito e o que se observa na prática, sob a perspectiva da participação cidadã feminina. Embora a Constituição de 1988 garanta a universalidade do direito ao voto e tenha assumido o compromisso de construir uma sociedade sem preconceitos de origem, raça, sexo, cor, idade e quaisquer outras formas de discriminação, a representação política das mulheres ainda reflete a desigualdade que caracteriza as relações de gênero na esfera pública.

Diversos estudos apontam que, embora o Brasil nas últimas décadas tenha avançado na pauta da igualdade de gênero em diversas frentes, por exemplo, a de acesso ao ensino superior, ainda existe um longo caminho a ser percorrido em outras áreas como remuneração e participação política (OLIVEIRA, 2014).

De acordo com dados divulgados pelo Instituto Brasileiro de Geografia e Estatística - IBGE, essa trajetória desigual, relacionada aos papeis de gênero, indicam que, apesar do percentual de mulheres que completaram a graduação, na faixa etária de 25 a 44 anos de idade, ser de $21,5 \%$ e o de homens ser de $15,6 \%$, no mercado de trabalho, as mulheres ganham menos. Os rendimentos médios do trabalho das mulheres correspondem em média a 
cerca de $3 / 4$ do que os homens recebem (IBGE, 2018).

No que se refere à participação política, a presença masculina é hegemônica e poucas mulheres conseguem se eleger para os cargos legislativos. Com base no resultado das eleições de 2018 e o total dos cargos em disputa, as mulheres passaram a representar $15 \%$ das vagas eleitas para Câmara dos Deputados e 13\% das vagas para o Senado (BRASII. Agência Senado, 2019).

Melo, uma vez mais, contribui com o debate ao afirmar que:

Uma sociedade digna de ser considerada democrática aos olhos dos próprios participantes precisa modificar os padrões de autoridade e poder que impossibilitam que as mulheres exerçam uma autonomia socialmente enraizada, isto é, que possam se autogovernar, sendo reconhecidas e respeitadas em seus modos de vida (MELO, 2017, p. 175).

A luta pelo reconhecimento do direito à igualdade de gênero, especialmente no que se refere aos direitos políticos e de participação efetiva nos espaços de poder, ainda é necessária e evidencia um estado de tensão entre o direito à igualdade formalmente previsto na Constituição de 1988 e a desigualdade histórica que se manifesta nas relações sociais. Sem a efetividade da participação cidadã, o Estado Democrático de Direito opera num nível simbólico, como um horizonte a ser ainda alcançado.

\section{A DESIGUALDADE DE GÊNERO E A SUB-REPRESENTAÇÃO DA MULHER NA ESFERA PÚBLICA NO BRASIL}

As relações de gênero historicamente são complexas e multifacetadas. Refletir sobre este tema e inserir-se no debate de alguma maneira contribui para que se avance na efetivação do direito de igualdade entre homens e mulheres. Basta lembrar que há algumas décadas essa discussão seria improvável e, se acontecesse, certamente, seria tida por inoportuna.

Quelen Brondani de Aquino discorre que:

[...] resta evidente que os papeis sociais, culturais, econômicos e políticos são influenciados pelo contexto em que estão inseridos. Diante desse contexto, a compreensão de alguns elementos são relevantes para que o discurso da igualdade de direitos seja ratificado nas práticas cotidianas da sociedade civil. Historicamente observada nas relações de gênero, a dominação masculina coloca-se como um dos grandes desafios para a promoção da equidade. Ela permanece presente especialmente no ambiente doméstico, redoma intransponível para o mundo público. [...] Diante dessas 
relações de gênero assimétricas, pode-se extrair que da instituição familiar resulta uma série de diferenças entre os papeis desempenhados por homens e mulheres na sociedade, conforme já mencionado, não apenas no ambiente doméstico, mas evidentemente das esferas públicas da sociedade. (AQUINO, 2014, p. 31, 39).

A ideia de esfera ou espaço público que se trabalha neste artigo é aquela descrita por Jürgen Habermas, como "uma rede adequada para a comunicação de conteúdos, tomadas de posição e opiniões; nela os fluxos comunicacionais são filtrados e sintetizados a ponto de condensarem em opiniões públicas enfeixadas em temas específicos.” (HABERMAS, 1997, p. 92). Deste modo, a esfera pública não seria uma instituição, uma organização, ou sistema, mas, sim, um fenômeno social que se reproduz através do agir comunicativo.

Na perspectiva habermasiana, Walter Reese-Schäfer ensina que a esfera pública compreende, então, o espaço comunicativo entre a esfera civil privada e o Estado, caracterizada pelo acesso livre, universal e desimpedido de todo o público, que se produz por meio do agir comunicativo (REESE-SCHÄFER, 2008, p. 175). Nesse mesmo sentido, Gabrielle Tatith Pereira compreende a política deliberativa, no que toca à legitimidade, como algo dependente de uma cidadania capaz de participar dos processos institucionalizados de formação da opinião pública e capaz de transformar o poder comunicativo em poder administrativo pela ação comunicativa dos cidadãos (PEREIRA, 2015). De acordo com Habermas:

Podemos fazer uma distinção entre poder produzido comunicativamente e poder empregado administrativamente. A partir daí, temos a esfera pública dominada por dois processos que se cruzam em sentido contrário: a produção comunicativa do poder legítimo, para a qual $\mathrm{H}$. Arendt esboçou um modelo normativo, e a obtenção da legitimação através do sistema político, através da qual o poder administrativo se torna reflexivo. (HABERMAS, 1997, p. 270).

Não é demais lembrar que a participação na esfera pública se dá entre pessoas livres e iguais, que exercem, comunicativamente, seu poder de influência e de crítica. E essa igualdade de participação na esfera pública e nas esferas de poder do Estado vem sendo sistematicamente negadas ou dificultadas às mulheres, em que pesem alguns avanços que podem ser observados, sobretudo a partir de meados do século $\mathrm{XX}$ : direito ao voto, participação no mercado de trabalho, acesso a áreas da educação e qualificação profissional, outrora somente acessíveis aos homens, inscrição de pauta de direitos na Constituição. 
De acordo com Rurion Soares Melo:

É inegável que para a teoria crítica feminista o diagnóstico em torno da subordinação das mulheres precisa incluir em seu escopo uma compreensão adequada sobre a esfera pública. Será na e pela esfera pública que tanto se materializam as experiências difusas, mais ou menos explícitas, de dominação de gênero quanto são desencadeadas as lutas feministas pela democratização da vida política nas sociedades contemporâneas (MELO, 2017, p. 173).

Também sob uma perspectiva habermasiana, José Adércio Leite Sampaio entende que a legitimidade democrática e participação cidadã, centra-se numa perspectiva discursiva ou comunicacional, em que a participação cidadã informada confere legitimidade democrática ao próprio sistema político, com o atendimento de pressupostos contrafactuais de uma democracia comunicacional, de caráter predominantemente procedimental, em que "todos se sintam parte do processo deliberativo, havendo atendimento da igualdade de voz, da consideração do ponto de vista dos afetados, do livre influxo de informações da sinceridade nas tratativas e do predomínio dos melhores argumentos na construção dos consensos" (SAMPAIO, 2004, p. 25).

De acordo com a lição de Habermas:

O Estado democrático de direito transforma-se num projeto, resultado e, ao mesmo tempo, mola de uma racionalização do mundo da vida, a qual ultrapassa as fronteiras do político. O único conteúdo do projeto é a institucionalização progressivamente melhorada dos processos de formação racional e coletiva da vontade, os quais não podem prejulgar os objetivos concretos dos participantes. Qualquer passo nesse caminho tem efeitos retroativos sobre a cultura política e as formas de vida, sem as quais não poderiam surgir formas de comunicação adequadas à razão prática. (HABERMAS, p. 276).

A desigualdade de gênero na política, tal como se manifesta no Brasil, confronta o Estado Democrático de direito e causa um déficit de legitimidade observável nos baixos índices de candidatas eleitas para os parlamentos. Embora se reconheçam avanços, a subrepresentação feminina na política é um dado constatável que precisa ser discutido pela sociedade, num debate franco e comprometido com sua superação.

\subsection{O RECONHECIMENTO DE DIREITOS DE IGUALDADE ÀS MULHERES NO}




\section{PLANO INTERNO E EXTERNO E AS REPERCUSSÕES NA LEGISLAÇÃO}

\section{BRASILEIRA}

A constatação da desigualdade de gênero na esfera púbica e na participação política é um dado concreto e de amplo reconhecimento no plano nacional e internacional. Desde meados do Século XX, a busca do compromisso dos Estados com meios de superação dessa situação vem sendo objeto de debates, convenções e pactos internacionais que repercutem na ordem jurídica interna dos países.

Dentre os diversos pactos internacionais firmados pelo Brasil e Conferências Internacionais das quais o Brasil participou (BRASIL, 2020), com foco na promoção dos direitos da mulher, destacam-se:

a) Convenção Interamericana Sobre a Concessão dos Direitos Civis à Mulher (1948) - reconheceu às mulheres os mesmos direitos civis de que gozam os homens. Promulgada no Brasil por meio do decreto no. 31.643, de 23 de outubro de 1952;Convenção sobre os Direitos Políticos da Mulher (1953) - determinou o direito ao voto em igualdade de condições para mulheres e homens, bem como a elegibilidade das mulheres para todos os organismos públicos em eleição e a possibilidade, para as mulheres, de ocupar todos os postos públicos e de exercer todas as funções públicas estabelecidas pela legislação nacional. A convenção foi aprovada pelo Brasil em 20 de novembro de 1955, por meio do decreto legislativo no. 123. Sua promulgação ocorreu em 12 de setembro de 1963, pelo decreto no. 52.476;

b) I Conferência Mundial sobre a Mulher (Cidade do México, 1975) - reconheceu diversos direitos relativos à integridade da mulher e o direito ao próprio corpo, além disso, foi declarado o período de 1975-1985 como "Década da Mulher". O ano de 1975 foi declarado como o Ano Internacional da Mulher;

c) Convenção Para Eliminar Todas as Formas de Discriminação Contra a Mulher - CEDAW (1979) - dispunha aos países participantes o compromisso do combate a todas as formas de discriminação para com as mulheres. No Brasil, o Congresso Nacional ratificou a assinatura, com algumas reservas, em 1984. Tais reservas foram suspensas em 1994 pelo decreto legislativo no. 26. Promulgada por meio do decreto no. 4.377, de 13 de setembro de 2002 ;

d) II Conferência Mundial sobre a Mulher (Copenhague, 1980) - foram avaliados os primeiros cinco anos da Década da Mulher e o Instituto Internacional de Pesquisa e Treinamento para a Promoção da Mulher (INSTRAW) foi convertido em um organismo 
autônomo no sistema das Nações Unidas;

e) III Conferência Mundial Sobre a Mulher (Nairóbi, 1985) - avaliou os progressos ocorridos até então e o Fundo de Contribuições Voluntárias das Nações Unidas para a Década da Mulher foi convertido no Fundo de Desenvolvimento das Nações Unidas para a Mulher (UNIFEM);

f) IV Conferência Mundial sobre a Mulher (Beijing, 95) - com o subtítulo "Igualdade, Desenvolvimento e Paz", a conferência trouxe uma nova agenda de reivindicações relativas aos direitos das mulheres e os Estados assumiram compromissos com foco no estabelecimento de políticas públicas. Foi assinada por 184 países, dentre os quais o Brasil, a Plataforma de Ação Mundial da Conferência propondo objetivos estratégicos e medidas para a superação da situação de descriminalização, marginalização e opressão vivenciadas pelas mulheres.

No plano interno, no Brasil, dentre os avanços ocorridos a partir da década de 1930, destacam-se:

a) o Decreto $\mathrm{n}^{\mathrm{o}} 21.076 / 1932$ - instituiu a Justiça Eleitoral no Brasil e o voto feminino, em âmbito nacional;

b) a Constituição de 1934 dispôs no seu artigo 108 que eleitores seriam os brasileiros de um ou de outro sexo, maiores de 18 anos, que se alistassem na forma da lei, consagrando, assim, na própria Constituição, o direito de voto às mulheres;

c) a Constituição de 1988 assegurou o voto universal e assumiu o compromisso de concretizar um Estado Democrático de Direito, em que homens e mulheres gozem de igualdade formal e material;

d) a Lei $n^{\circ} 9.100 / 1995$, que estabeleceu normas para a realização das eleições municipais de 1996, trouxe em seu artigo 11, parágrafo $3^{\circ}$ que vinte por cento, no mínimo, das vagas de cada partido ou coligação deveriam ser preenchidas por candidaturas de mulheres;

e) a Lei $n^{\circ} 9.405 / 1997$, em sua redação original, estabeleceu no seu artigo 10, $\S$ $3^{\circ}$, que do número de candidatos a que cada partido ou coligação poderia registrar, deveria ser reservado o mínimo de trinta por cento e o máximo de setenta por cento para cada sexo;

f) A Lei $n^{\circ} 12.034 / 2009$ retificou o art. 10, $\S 3^{\circ}$, da Lei $n^{\circ} 9.504 / 1997$, para fazer constar expressamente "Do número de vagas resultante das regras previstas neste artigo, cada partido ou coligação preencherá o mínimo de 30\% (trinta por cento) e o máximo de $70 \%$ 
(setenta por cento) para candidaturas de cada sexo" (BRASIL, 2020).

As conferências internacionais, o movimento feminista e a ampliação do debate acadêmico influenciaram a política interna brasileira, de modo que, no plano formal, diversos mecanismos foram criados para promover a igualdade de gênero, inclusive na política. Ocorre que a realidade nem sempre se conforma de maneira automática às previsões normativas abstratas. Observe-se, por exemplo, a implantação das cotas de gênero nas eleições proporcionais. Com clara influência da Conferência Mundial Sobre a Mulher, ocorrida em Beijim, em 1995, a legislação brasileira buscou adotar política afirmativa de inclusão das mulheres em percentual mínimo a ser observado pelos partidos políticos e coligações no registro de candidaturas aos cargos proporcionais.

Num primeiro momento, fixou-se uma cota de $20 \%$ e, posteriormente, $30 \%$. Entretanto, os partidos políticos sempre buscaram contornar essa indicação, interpretando-a como uma recomendação e não uma imposição legal. Sob essa perspectiva, bastaria reservar a cota direcionada ao gênero feminino, que não precisaria necessariamente ser preenchida, e continuavam apresentando em número completo os registros de candidatos masculinos. Foi preciso que a Lei $\mathrm{n}^{\mathrm{o}}$ 12.034/2009 deixasse expresso que a cota deveria ser aplicada sobre o número de candidatos apresentados.

A luta pelo reconhecimento do direito à igualdade de gênero, especialmente no que se refere aos direitos políticos e de participação efetiva nos espaços de poder, ainda é necessária, e evidencia um estado de tensão entre o direito à igualdade formalmente expresso na Constituição de 1988 e a desigualdade histórica que se manifesta nas relações sociais.

\subsection{A SUB-REPRESENTAÇÃO FEMININA NOS PARLAMENTOS E A COTAS DE GÊNERO.}

Como decorrência dos compromissos assumidos pelo Brasil no plano internacional e do debate interno sobre a participação das minorias, aprovaram-se, a partir de meados dos anos 1990, instrumentos legislativos com o intuito de assegurar a efetiva participação das mulheres na política, sob a ótica do preenchimento dos cargos legislativos.

Em relação à composição dos parlamentos, o Brasil encontra-se ainda bastante aquém das democracias mais avançadas e bem atrasado em relação a países que também se encontram em fase de desenvolvimento. Mesmo em relação aos demais países da América Latina, a posição do Brasil no ranking de participação das mulheres no parlamento não é 
favorável:

No cenário internacional, o Brasil ocupava, em dezembro de 2017, a 152a posição entre os 190 países que informaram à Inter- Parliamentary Union IPU19 o percentual de cadeiras em suas câmaras baixas (câmara de deputados) ou parlamento unicameral ocupadas por mulheres em exercício (CMIG 44), com 10,5\%. Foi o pior resultado entre os países sulamericanos. No mundo, as mulheres ocupavam $23,6 \%$ dos assentos nas câmaras baixas ou parlamentos unicamerais (IBGE, 2018).

Conforme dados disponíveis no sítio eletrônico do Tribunal Superior Eleitoral TSE, nas eleições de 2018, o gênero feminino representava 52,5\% do eleitorado. Entretanto, $31,6 \%$ das candidaturas registradas correspondiam ao gênero feminino. A composição das vagas eleitas para o Parlamento, por outro lado, reflete uma sub-representação ainda maior: das vagas em disputa, foram eleitas Senadoras e Deputadas Federais, respectivamente, 15\% e 13\% para as Casas Legislativas congressuais (BRASIL, Tribunal Superior Eleitoral, 2018). A análise desses dados indica que os partidos políticos, praticamente, apenas cumpriram o patamar mínimo de candidaturas femininas exigidas pela cota de gênero prevista no artigo 10, $\S 3^{\circ}$, da Lei ${ }^{\circ}$ 9.504/1997 (BRASIL, 1997).

O que se observa é que, apesar da Constituição de 1988 ter assumido uma patuda de direitos que inclui demandas femininas e assegurado a igualdade como princípio a ser implementado do ponto de vista formal e material, a experiência ordinária tem demonstrado que o processo de inclusão efetiva da mulher nos espaços públicos, em geral, e na política, em particular, é lento e instável, atrelado a diversas variáveis como desenvolvimento humano e político, acesso à educação, implementação de políticas públicas, dentre outros.

Em reflexão sobre a participação das mulheres no poder e as cotas na política, Christiane Oliveira Silva e também Letícia Coutinho Aguiar argumentam que:

Não são poucos os estudos que evidenciam as causas da sub-representação feminina na política. Muitos argumentos se repetem, entre eles o de que as mulheres ainda são minoria no cenário político brasileiro e, por isso, sua ínfima participação não raras vezes, justifica-se pela própria ausência, afirmando-se, sem lastro, tratar-se de falta de interesse ou falta de vocação política. Também se aponta como causa o fato de que mulheres não costumam votar em outras mulheres; ou, ainda, afirma-se, com assertividade, que o fato de as direções partidárias, em sua maioria, serem compostas por homens, impede, ou dificulta enormemente, que se recrutem mulheres para compor chapas de candidaturas nas eleições (SILVA; AGUIAR, 2020, p. 92). 
Esses argumentos apontados por Silva e Aguiar (2020), geralmente saídos do senso comum, e largamente utilizados para justificar a baixa participação feminina nas esferas de poder deixam em evidência a desigualdade de gênero que se perpetua na esfera pública e com a qual se convive, quase que naturalmente. Para que essa realidade seja superada, propõe-se ampliar o debate sobre quais outras possibilidades de políticas públicas, para além das cotas na apresentação de candidaturas, poderiam ser implementadas.

\section{SUPERAÇÃO DA DESIGUALDADE DE GÊNERO NA POLÍTICA: POSSÍVEIS CAMINHOS}

A desigualdade de tratamento conferido ao gênero feminino compreende aspectos atrelados a preconceitos de origem social, religiosa, política e histórica. Sabe-se que a desigualdade de gênero na esfera pública em geral e na representação feminina nos quadros do Legislativo, em particular, é uma situação que se mostra incompatível com o paradigma do Estado Democrático de Direito.

O desafio de se superar essa situação de desigualdade é uma luta que implica na conformação de comportamentos e expectativas que vão além da eleição de mulheres para os parlamentos, mas que também passa por esse prisma. Não é possível afirmar que o aumento do número de mulheres no parlamento, por si só, refletiria numa melhora qualitativa do debate público; entretanto, é possível dizer que, sendo as mulheres a maioria da população e dos eleitores, a sub-representação delas no parlamento constitui um déficit de legitimidade democrática.

Sob qualquer perspectiva que se encare, seja do ponto de vista majoritário, uma vez que as mulheres constituem a maioria da população; seja do ponto de vista da concretização dos direitos fundamentais, não se pode chamar efetivamente democrático um Estado no qual o processo político não possibilita a efetiva participação de segmentos majoritários estatisticamente, mas minoritários na representatividade de suas identidades e demandas.

Um dos mecanismos que vêm sendo utilizados como política pública de superação das situações de desigualdade é a adoção de cotas que permitam relativa igualdade nas condições de saída ou de chegada. Por meio das cotas, reserva-se um número de vagas entre os concorrentes ou entre os cargos que se visa a preencher. Essas vagas ou cargos reservados são destinados ao grupo minoritário ou marginalizado a que se deseja afirmar. 


\title{
Conforme Carmén Lúcia Antunes Rocha:
}

\begin{abstract}
A ação afirmativa é um dos instrumentos possibilitadores da superação do problema do não-cidadão, daquele que não participa política e democraticamente como lhe é, na letra da lei fundamental, assegurado, porque não se lhe reconhecem os meios efetivos para se igualar com os demais. Cidadania não combina com desigualdade. República não combina com preconceito. Democracia não combina com discriminação (ROCHA, 1996, p. 295).
\end{abstract}

Desde que implantou o sistema de cota para mulheres nas eleições (a lei referia-se a vagas para mulheres e não percentual de gênero), por meio da Lei $n^{\circ}$ 9.100/1995, o Brasil adotou o sistema de cotas legais, ao estabelecer que $20 \%$ (vinte por cento), no mínimo das vagas de cada partido ou coligação, deveriam ser preenchidas por candidaturas de mulheres. Atualmente, a Lei $n^{\circ}$ 9.504/97 estabelece que do número de candidatos apresentados para concorrer às vagas dos cargos proporcionais, cada partido (não é mais possível coligação na disputa de cargos não majoritários) preencherá o mínimo de 30\% (trinta por cento) e o máximo de $70 \%$ (setenta por cento) para candidaturas de cada sexo.

O sistema de cotas voluntárias, que ocorre quando os partidos, voluntariamente, estipulam em seus estatutos um percentual de vagas a ser reservado para cada gênero, nunca chegou a ser implantado no Brasil; pois constata-se forte resistência dos partidos políticos em adotar políticas efetivas de incentivo à participação das mulheres. Nesse sentido, discute-se na sociedade e no Congresso Nacional a implantação das cotas de gênero também na formação dos órgãos diretivos partidários.

A realidade brasileira vem reafirmando, a cada eleição, que a simples adoção de cotas legais para o registro de candidaturas não foi suficiente, em 25 anos de sua implantação, para inserir um maior contingente de mulheres na política e nem para aumentar de maneira minimamente significativa a participação feminina na formação das casas legislativas. Essa constatação tem levado a sociedade a ampliar o debate sobre quais alternativas seriam viáveis.

Atualmente, tramitam no Congresso Nacional diversos projetos de lei que incentivam a participação política feminina e de combate à discriminação de gênero. O Senado analisa pelo menos sete proposições, das quais são cinco projetos de lei e duas propostas de emenda à Constituição: Projeto de Emenda à Constituição $n^{\circ}$ 38/2015, Projeto de Emenda à Constituição $n^{\circ}$ 81/2019, Projeto de Lei $n^{\circ}$ 1541/2019, Projeto de Lei $n^{\circ} 2235 / 2019$, Projeto de Lei $n^{\circ}$ 2913/2019, Projeto de Lei $n^{\circ} 4391 / 2020$ e Projeto de Lei do Senado 332/2015 
(BRASIL. Agência Senado, 2020).

Dentre as propostas que estão sendo discutidas no Congresso Nacional e pela sociedade estão: mudança do sistema eleitoral com implantação do voto proporcional com listas fechadas e regra de alternância de gênero; financiamento de campanha; previsão legal de punição para os partidos que não cumprirem as leis quanto as cotas de gênero; adoção de cotas voluntárias pelos partidos políticos (BRASIL. Senado Federal, 2019).

Além da discussão que ocorre no âmbito da sociedade e do Congresso Nacional, tem-se observado uma postura mais ativa do Poder Judiciário em ampliar o alcance das cotas de gênero já previstas em lei. Nesse sentido, em pelo menos três oportunidades recentes o Poder Judiciário reafirmou a política afirmativa de gênero nas eleições:

a) o Supremo Tribunal Federal, no julgamento da Ação Direta de Inconstitucionalidade (ADI) 5617, em 15 de março de 2018, decidiu que os recursos do Fundo Partidário, destinado ao financiamento de campanhas eleitorais, deve observar a proporcionalidade de gênero das candidaturas de modo que se observe o patamar mínimo de 
$30 \%$ de candidaturas femininas, conforme previsto no artigo 10 , parágrafo $3^{\circ}$, da Lei $\mathrm{n}^{\mathrm{o}}$ 9.504/1997 (BRASIL. Supremo Tribunal Federal, 2018);

b) o Tribunal Superior Eleitoral, por meio do artigo 17, parágrafo $4^{\circ}$, da Resolução $n^{\circ}$ 23.604/2019, estabeleceu que os partidos políticos devem destinar no mínimo $30 \%$ (trinta por cento) do montante do Fundo Especial de Financiamento de Campanha (FEFC) para aplicação nas campanhas de suas candidatas (BRASIL, 2019);

c) o Tribunal Superior Eleitoral, em ações eleitorais oriundas de Valença (Estado do Piauí) e Imbé (Estado do Rio Grande do Sul), cassou os diplomas de vereadores eleitos por chapas que usaram candidaturas femininas fraudulentas para alcançar o percentual mínimo de 30\%, referente à cota de gênero nas eleições de 2016 (BRASIL. Tribunal Superior Eleitoral, 2020).

As repercussões dessa participação ativa do Judiciário nas ações afirmativas de gênero na política serão sentidas nas eleições municipais de 2020. Resta verificar se haverá um incremento na eleição de vereadoras ou se tudo continuará como antes, com as mulheres sendo sub-representadas nas Câmaras Municipais. A experiência dessas eleições também servirá de termômetro para as próximas eleições gerais de 2022, quando estarão em disputa as vagas para Câmara Federal e o Senado.

Para que se supere a dissimetria entre homens e mulheres na política e numa perspectiva de participação cidadã, deve-se aprofundar o debate acerca das políticas afirmativas adotadas até aqui, seus resultados e perspectivas, vislumbrando, inclusive, novas possibilidades. Ampliar o âmbito de incidência das cotas é uma possibilidade, porém, essa ampliação requer mecanismos de efetividade que superem o mero preenchimento de vagas reservadas e que se combatam as fraudes que desvirtuem a política afirmativa.

O debate acerca das possibilidades de incremento das políticas afirmativas de gênero nas eleições precisa ser ampliado e alcançar a sociedade como um todo. E de maneira especial, deve-se envolver ainda mais os partidos políticos, mediadores da democracia representativa. Numa democracia de partidos políticos, como é o caso do Brasil, não se avançará na pauta da igualdade de gênero, sem se avançar também na discussão acerca da democracia interna dos partidos políticos.

\section{CONSIDERAÇÕES FINAIS}

O presente artigo buscou discutir, sob o paradigma do Estado Democrático de 
Direito, em que medida a aplicação da cota de gênero tem contribuído para fomentar a representatividade feminina na política. Como ponto de partida, viu-se que a Constituição de 1988 trouxe um redimensionamento de sentido da cidadania e do pluralismo político para além do entendimento restritivo tradicional de poder votar, ser votado e haver partidos políticos. Nesse paradigma em que o poder político emana do povo, a cidadania passa a ser o canal comunicativo, por meio do qual se forma a vontade política, a partir da síntese discursiva dos variados atores sociais, com seus diferentes projetos de vida, tal como deve ser o pluralismo político democrático.

Por outro lado, constatou-se que há uma dissociação entre o ideal de Estado Democrático de Direito e a realidade vivenciada, pois embora a Constituição de 1988 garanta a universalidade do direito ao voto e tenha assumido o compromisso de construir uma sociedade sem preconceitos de origem, raça, sexo, cor, idade e quaisquer outras formas de discriminação, a representação política das mulheres ainda reflete a desigualdade que caracteriza as relações de gênero na esfera pública.

A desigualdade de gênero na política, que no Brasil repercute nos baixos índices de candidatas eleitas para os parlamentos, contrasta o ideal de legitimação democrática e participação cidadã. A sub-representação feminina na política é um dado que precisa ser discutido pela sociedade, num debate franco e comprometido com sua superação. Se por um lado, não se pode afirmar que mais mulheres na política necessariamente melhoraria o nível do debate ou a qualidade do Poder Legislativo, não se pode deixar de reconhecer, por outro lado, que, sendo as mulheres a maioria da população e dos eleitores, a sub-representação feminina na política traz consigo um déficit de legitimidade democrática.

Observa-se que a cota de gênero nas eleições proporcionais, conforme previsto na Lei $n^{\circ}$ 9.504/97, é a principal ação afirmativa adotada pelo Brasil para superar a assimetria entre homens e mulheres na política. Entretanto, passados 25 anos de sua implantação, desde a Lei no 9.100/1995, não se pode afirmar que tenha produzido resultados satisfatórios, uma vez que o Brasil figura como um dos países em que as mulheres têm menores percentuais de participação nos parlamentos.

Ainda que a efetividade da cota de gênero nas eleições atue num plano simbólico, não se pode dizer que ela seja desimportante, na medida em que sinaliza um caminho a ser seguido e a partir dela se estrutura todo o debate acerca das possibilidades de ampliação das políticas afirmativas de incentivo à participação das mulheres na política. 
A trajetória de afirmação da igualdade de gênero é uma construção histórica que no Brasil teve avanços significativos a partir a Constituição de 1988. Entretanto, a superação da assimetria existente entre homens e mulheres nos espaços de poder demandam o engajamento de todos, cidadãos e instituições, com vistas à concretização do Estado Democrático de Direito em sua plenitude. Para isso, o debate sincero, o reconhecimento dos avanços e desafios ainda por superar, bem como as possibilidades de alternativas, é essencial para que se estabeleça um agir comunicativo, por meio do qual a participação cidadã exerça verdadeiramente seu poder de influência e crítica.

\section{REFERÊNCIAS BIBLIOGRÁFICAS:}

ALMEIDA, Jéssica Teles de. Análise da participação política feminina no paradigma do Estado Democrático de Direito brasileiro. Suffragium R. Trib. Reg. Eleit. do Ceará, Fortaleza, v. 7, n. 12, p. 1-174, jul./dez. 2015.

AQUINO, Quelen Brondani de. A gestão das políticas públicas de gênero: uma análise ao Plano Plurianual 2010-2013 e 2014-2017 enquanto política pública de empoderamento e autonomia da mulher no Município de Santa Cruz do Sul - RS. Dissertação (Mestrado em Direito) - Universidade de Santa Cruz do Sul - UNISC, Santa Cruz do Sul, 2014. Disponível em

https://repositorio.unisc.br/jspui/bitstream/11624/1302/1/Quelen\%20Brondani\%20de\%20Aqu ino.pdf. Acesso em: 7 set. 2020.

BRASIL. Congresso Nacional. Senado Federal. Agência Senado. Minoria no Congresso, mulheres lutam por mais participação Senado Notícias. Disponível em:

https://www12.senado.leg.br/noticias/materias/2019/03/07/minoria-no-congresso-mulhereslutam-por-mais-participacao. Acesso em: 13 set. 2020.

BRASIL. Congresso Nacional. Senado Federal. Agência Senado. Propostas em análise no Senado ampliam participação da mulher na política. Disponível em:

https://www12.senado.leg.br/noticias/materias/2020/09/02/propostas-em-analise-no-senadoampliam-participacao-da-mulher-na-politica. Acesso em: 13 set. 2020.

BRASIL. Congresso Nacional. Senado Federal. Procuradoria Especial da Mulher. Mais mulheres na política: retrato da sub-representação feminina no poder. Disponível em: https://www12.senado.leg.br/institucional/procuradoria/proc-publicacoes/livreto-maismulheres-na-politica. Acesso em: 13 set. 2020.

BRASIL. [Constituição (1988)]. Constituição da República Federativa do Brasil de 1988. Brasília, DF: Presidência da República, [2020]. Disponível em:

http://www.planalto.gov.br/ccivil_03/constituicao/constituicao.htm. Acesso em: 7 set. 2020.

BRASIL. Lei $\mathbf{n}^{\circ}$ 9.100, de 29 de setembro de 1995. Estabelece normas para a realização das 
eleições municipais de 3 de outubro de 1996, e dá outras providências. Brasília, DF: Presidência da República, [2020]. Disponível em http://www.planalto.gov.br/ccivil_03/leis/L9100.htm\#: :text=LEI\%20N\%C2\%BA\%209.100 $\%$ 2C\%20DE\% 2029\%20DE\%20SETEMBRO\%20DE\% 201995.\&text=Estabelece\%20normas \%20para\%20a\%20realiza\%C3\%A7\%C3\%A3o,Art. Acesso em: 7 set. 2020.

BRASIL. Lei $\mathbf{n}^{0}$ 9.504, de 30 de setembro de 1997. Estabelece normas para as eleições. Brasília, DF: Presidência da República, [2020]. Disponível em http://www.planalto.gov.br/ccivil_03/leis/19504.htm. Acesso em: 7 set. 2020.

BRASIL. Lei $\mathbf{n}^{\mathbf{0}}$ 12.034, de 29 de setembro de 1995. Altera as Leis $\mathrm{n}^{\mathrm{os}} 9.096$, de 19 de setembro de 1995 - Lei dos Partidos Políticos, 9.504, de 30 de setembro de 1997, que estabelece normas para as eleições, e 4.737, de 15 de julho de 1965 - Código Eleitoral. Brasília, DF: Presidência da República, [2020]. Disponível em http://www.planalto.gov.br/ccivil_03/_Ato2007-2010/2009/Lei/L12034.htm. Acesso em: 7 set. 2020.

BRASIL. Observatório Brasil da Igualdade de Gênero. Principais Documentos Internacionais para a Promoção dos Direitos das Mulheres e da Igualdade de Gênero. Disponível em: http://www.observatoriodegenero.gov.br/eixo/internacional/documentosinternacionais. Acesso em 07/08/2020.

BRASIL. Supremo Tribunal Federal. Imprensa. STF garante mínimo de $30 \%$ do fundo partidário destinados a campanhas para candidaturas de mulheres. Notícias STF, 2018. Disponível em: http://www.stf.jus.br/portal/cms/verNoticiaDetalhe.asp?idConteudo=372485. Acesso em: 13 set. 2020.

BRASIL. Tribunal Superior Eleitoral. Comunicação. Decisões e normas do TSE combatem tentativas de fraude à cota de gênero nas eleições. Disponível em:

http://www.tse.jus.br/imprensa/noticias-tse/2020/Agosto/decisoes-e-normas-do-tse-

combatem-tentativas-de-fraude-a-cota-de-genero-nas-eleicoes. Acesso em 13 set. 2020.

BRASIL. Tribunal Superior Eleitoral. Estatísticas eleitorais. Disponível em: http://www.tse.jus.br/eleicoes/estatisticas/estatisticas-eleitorais. Acesso em 13 set. 2020.

BRASIL. Tribunal Superior Eleitoral. Resolução 23.607, de 17 de dezembro de 2019. Dispõe sobre a arrecadação e os gastos de recursos por partidos políticos e candidatos e sobre a prestação de contas nas eleições. Diário da Justiça Eletrônico - DJE-TSE, nº 249, de 27 dez. 2019 e republicada no Diário da Justiça Eletrônico - DJE-TSE, nº 249, de 19 ago. 2020, p. 105-147. Disponível em: http://www.tse.jus.br/legislacao/compilada/res/2019/resolucao-no-23-607-de-17-dedezembro-de-2019. Acesso em: 13 set. 2020.

HABERMAS, Jürgen. Direito e democracia: entre facticidade e validade. Tradução: Flávio Beno Siebeneichler. Rio de Janeiro: Tempo Brasileiro, 1997. v. 2.

INSTITUTO BRASILEIRO DE GEOGRAFIA E ESTATÍSTICA. Coordenação de População e Indicadores Sociais. Estatísticas de gênero: indicadores sociais das mulheres no Brasil. n.

Revista Brasileira de Filosofia do Direito | e-ISSN: 2526-012X | Encontro Virtual | v. 6 | n. 2 |

p. $55-74$ | Jul/Dez. 2020. 
38. Rio de Janeiro: IBGE, 2018. Disponível em:

https://biblioteca.ibge.gov.br/visualizacao/livros/liv101551_informativo.pdf. Acesso em: 13 set. 2020.

KUHN, Thomas Samuel. A estrutura das revoluções científicas. Tradução: Beatriz Vianna Boeira e Nelson Boeira. 12. ed. São Paulo: Perspectiva, 2013. (Debates; 115) Título original: The structure of scientific revolutions.

MELO, Rurion Soares. Dominação de gênero e esfera pública na teoria crítica feminista.

Revista Ideação. Universidade Estadual de Feira de Santana. n. 36, jul./dez. 2017. Disponível em: file:///C:/Users/maxwe/Dropbox/My\%20PC\%20(LAPTOP-

8HC4PASA)/Downloads/3153-12889-1-PB.pdf. Acesso em: 07 set. 2020.

OLIVEIRA, Kamila Pagel de. A trajetória da mulher na política brasileira: as conquistas e a persistência de barreiras. Cadernos da Escola do Legislativo. Belo Horizonte: Assembleia Legislativa do Estado de Minas Gerais, Escola do Legislativo. v.16, n.26, ago./dez. 2014. Disponível em:

https://dspace.almg.gov.br/bitstream/11037/18488/1/Cadernos\%20da\%20Escola\%20do\%20L egislativo\%2026.pdf. Acesso em: 13 set. 2020.

PEREIRA, Gabrielle Tatith. Representação política, judicialização e democracia: o resgate do político por meio da interação entre o parlamento e a esfera pública. SILVA, Rafael Silveira e; MENEGUIN, Fernando Borato (Org.). Resgate da reforma política: diversidade e pluralismo no legislativo. Brasília : Senado Federal, Coordenação de Edições Técnicas, 2015.

REESE-SHÄFER, Walter. Compreender Habermas. Tradução: Vilmar Schneider. Petrópolis, RJ: Vozes, 2008. (Série Compreender).

ROCHA, Cármen Lúcia Antunes. Ação afirmativa: o conteúdo democrático do princípio da igualdade jurídica. Revista de informação legislativa. Brasília: Senado Federal, Subsecretaria de Edições Técnicas, v. 33, n. 131, jul./set. 1996. Disponível em: http://www2.senado.leg.br/bdsf/handle/id/496863. Acesso em: 13 set. 2020.

SAMPAIO, José Adércio Leite. Teorias constitucionais em perspectiva: em busca de uma constituição pluridimensional. SAMPAIO, José Adércio Leite (Org.). Crise e desafios da constituição: perspectivas críticas da teoria e das práticas constitucionais brasileira. Belo Horizonte: Del Rey, 2004.

SILVA, Christiane Oliveira; AGUIAR, Letícia Coutinho. Mulheres no poder: cotas femininas para participação na política. Estudos Eleitorais. Brasília, v. 14, n. 1, ed. especial, p. 8-285, jan/abr, 2020.

SILVA, José Afonso. Curso de Direito Constitucional Positivo. 15. ed. São Paulo: Malheiros, 1998. 